\title{
Commentary
}

\section{Making a "Pledge": Moral Suasion and Health Promotion Practice}

\author{
Glenn Laverack \\ Unit for Health Promotion Research, University of Southern Denmark, Niels Bohrs Vej 9-10, \\ DK-6700 Esjberg, Denmark; grlavera@hotmail.com
}

Received: 18 September 2018; Accepted: 24 October 2018; Published: 26 October 2018

\begin{abstract}
Moral suasion offers a versatile and low-cost approach to influence social norms and risky health behaviours, but is often neglected in health promotion in favour of using educational approaches. The purpose of this paper is to discuss the challenges and the benefits of using moral suasion in health promotion. Past and present experiences of using moral suasion to promote health are discussed in conjunction with other approaches, such as harm reduction. The challenge of using moral suasion as an approach is that it focuses on individual behaviour change, rather than addressing the broader structural causes of poor health. However, the paper concludes that the versatility of the moral suasion approach and the success of using "pledges" means that it can be an important intervention, alongside other educational and motivational techniques, to help to change behaviours at the individual and collective levels.
\end{abstract}

Keywords: health promotion; moral suasion; harm reduction; fear-based interventions; health coaching; pledges; motivational interviewing

\section{Introduction}

Moral suasion is a form of persuasion using moral reasoning to influence the beliefs and behaviours of individuals and groups. Moral suasion can be used to communicate health messages and to highlight personal resources to help change people's attitudes and actions [1]. Moral suasion is associated with "soft power", the ability to obtain what one wants through indirect actions to persuade others to voluntarily do what you want them to do, but by avoiding conflict [2]. Moral suasion is also associated with "expert power" in which a person attributes superior knowledge and skills to another person, such as to a doctor which then grants him/her the right to prescribe a behaviour which the person accepts an obligation to comply with. The legitimate professional position is accepted, and this results in people listening to the moral argument and carrying out the advice to change a risky behaviour [3]. Moral suasion offers a versatile and low-cost health promotion approach because it can be readily used in many settings as a part of ongoing face-to-face communication activities to influence social norms and risky health behaviours. However, it has been neglected in favour of using educational approaches that rely on communication channels using, for example, the mass and social media.

The purpose of this paper is to discuss the benefits and the challenges of using a moral suasion approach in health promotion by drawing on the literature and, in particular, discussing the use of individual and collective "pledges". Firstly, examples from the past and present experiences of using moral suasion to promote health are discussed. 


\section{Past Experiences of Using Moral Suasion}

Historically, moral suasion has been adapted to promote collective action and to create leverage for political and economic change through government policy. It has also been used to radically influence social norms in regard to alcohol consumption and women's rights on foot-binding.

\subsection{Moral Suasion and Alcohol Consumption}

The temperance movement used a strategy of moral suasion to oppose the drinking of alcohol to the point of total abstinence in the United Kingdom in the 19th century, working across the social classes [4]. The strategy established a mass movement encouraging mostly men to take a "pledge" to cease from the use of alcohol because of its socially harmful consequences, the moral argument. The "pledge" was made in the presence of other people, and this created a strong moral pressure to conform, supported by the movement through self-help groups.

\subsection{Moral Suasion and Foot-Binding}

Foot-binding is a painful and dangerous practice that was universally used in China for a millennium, but which ended, for the most part, in a single generation. The natural-foot movement was championed by liberal modernizers and women's rights advocates, and developed in the years of change, culminating in the "Revolution of 1911". These reforms consequently provided alternative opportunities of financial support for women strengthening their independence and bargaining power. The natural-foot movement used moral suasion by forming alliances, called "pledge associations", of parents who promised (by making a pledge) not to foot-bind their daughters nor let their sons marry foot-bound women on the moral basis that this was a harmful and degrading practice [5].

\section{Present Day Experiences of Using Moral Suasion}

The historical lessons learned about the success of making a "pledge" has led to moral suasion been adapted to promote broader collective action and to create leverage for favourable policy change. In particular, the use of "pledges" have become an important tactic to address chronic diseases, including for promoting a tobacco-free environment. In Australia, for example, an initiative by not-for-profit and financial organisations, in collaboration with UN agencies, formed the "Tobacco-Free Finance Pledge" to encourage tobacco-free finance policies across lending, insurance, and investment. Signatories pledged to be part of the solution to ensure a tobacco-free world, to raise awareness of the issue and to encourage the transition away from investing in tobacco companies [6]. Other present-day experiences of moral suasion in health programs also use "pledges" and include women's rights on reproductive health and for promoting healthy lifestyles.

\subsection{Moral Suasion and Female Genital Mutilation}

An important element in mobilizing communities in the fight against female genital mutilation (FGM) has been moral suasion. Collective declarations to abandon FGM can take different forms, including many people signing a statement, alternative rites of passage celebrations, and multi-village gatherings. When collective declarations are made, this suggests that a sufficient number of individuals have decided, on moral grounds, not to harm their children by allowing cutting. These collective declarations can then mark a final decision to abandon FGM, or are a milestone that signifies readiness for change, and indicates that further support is needed to sustain and accelerate the process of abandonment [7]. Tostan is a non-government organisation working for positive social transformation and the abolishment of FGM that has had some success using moral suasion in Africa. Tostan has made claims that the rate of women reporting they did not have the intention to cut their daughter was three times higher than in control villages. The success of the overall program was through strong local leadership and an approach to help people to empower themselves though education and income 
generation. Moral suasion was achieved through the use of collective declarations or pledges not to cut girls in their community [8].

\subsection{Moral Suasion and Health Coaching}

The promotion of a healthy lifestyle is a significant part of modern health promotion practice that regularly uses persuasion, coercion, and a moral suasion approach. Health coaching is based on developing a dialogue and using clinical interventions to engage with clients at risk for chronic conditions to help them change their unhealthy behaviours [9]. Health coaching has been shown to be effective in managing type 2 diabetes, for example, after six months, individuals who were coached showed improvements in medication adherence in comparison to a non-coached control group [10]. Another study on reducing total cholesterol levels in patients of coronary heart disease achieved a significantly greater improvement in coached patients compared to non-coached patients, as well as secondary outcomes, such as weight loss, increased physical activity, and a reduction in anxiety [11]. A further study concluded that, after 12 months, the coached participants had a 32\% smoking quit rate, compared to $18 \%$ for non-participants. A further $11 \%$ of participants who did not quit smoking did report a reduction in tobacco use, an indication that they would quit in the future [12].

The health coaching process begins by building a relationship with the client through a dialogue that allows for moral suasion to be used often through motivational interviewing. Motivational interviewing can raise awareness about barriers to behaviour change, but it can also be used to apply moral pressure to initiate a desire to change. A new vision, often expressed as a written statement (a "pledge"), is developed to provide a direction to improve individual health. The statement allows the client to visualize their potential for change and sets goals, often worded as a partnership between the health coach and the client, to track progress but also to persuade the client into changing their behaviour. The health coach helps the client to focus on success and positive feedback encourages them to maintain their "pledge". "Healthtrainers", for example, is a free health coaching service funded by the UK National Health Service to help people to make positive and sustainable lifestyle changes in regard to weight loss, healthy eating, physical activity, and alcohol consumption. The health trainers offer one-to-one advice for up to three months, but this is limited to a weekly meeting to discuss progress towards achieving personal goals and to resolve any barriers to changing behaviour. This means that approaches such as moral suasion can be an attractive option to the health trainer to persuade people to commit to a "pledge" and to, at least indirectly, apply moral pressure when they meet, to maintain their promise of a healthier lifestyle. The relationship between the practitioner and the client is dependent on an acceptance of the expert power of the health coach, who can then use their power of persuasion to leverage behaviour change [13].

Fear-based approaches can be used alongside moral suasion, but only if they have been rigorously tested with the target audiences to ensure they produce the intended changes in awareness, attitudes, and behavioural intentions. Practitioners should also ensure that interventions are backed up with a supportive environment to enable people to easily act upon any negative information, including those who have strong defensive reactions or who feel that it is irrelevant to their own lives [14]. Fear-based approaches essentially use the threat of, or a "moral argument" against, harmful consequences for starting or continuing a particular high-risk behaviour. However, fear-based approaches can have a negative effect, in which the client reaction is the opposite to the intended effect of the advice, especially in young adults in regard to safer behaviours [15]. A harm reduction approach has also be used alongside moral suasion to manage the harmful consequences from needle exchange, opioid substitution therapy, substance use prevention for adolescents, and smoking cessation [16]. A harm reduction intervention in the United States, for example, used brief motivational interviews to reduce alcohol-related consequences among adolescents (aged 18-19 years) treated in an emergency room following an alcohol-related event. The goal of harm reduction is to work with individuals on their terms and in their context, whereas moral suasion tends to enhance the user's guilt and feelings of stigma. The harm reduction approach is based on acceptance [17], and can be used as an 
intervention consecutively with a more moral approach, for example, to reduce alcohol consumption. Campaigns have promoted the adoption of having alcohol-free days every week, in addition to the more radical (moral) approach of complete abstinence for a whole month or to totally going sober [18].

\section{The Challenge of Using Moral Suasion}

The challenge of using moral suasion as an approach in health promotion is that it focuses on individual behaviour change, rather than addressing the broader structural causes of poor health. This can be exacerbated by changes in health promotion advice, for example, regarding alcohol consumption, and by a professional reliance on simple health messaging. When health promotion campaigns fail to convince people to follow expert advice and to change to healthier behaviours, there has been a tendency to "blame the victim". This can reinforce a person's sense of isolation and self-blame and can lead to feelings of distrust, for example, for drinking too much alcohol or for continuing to smoke. Ethically, even if people know that certain behaviours are harmful to their health, it should be their decision, based on an informed choice, to continue to do so or not. Promoting autonomy, rather than attempting to control and restrict choice, offers the greater prospect of promoting health, and is core to an ethical approach to health promotion.

In reality, the reasons for people engaging in unhealthy behaviours are complex, and are not simply influenced by access to information. The challenge of focusing at an individual level, in an environment of changing advice about a healthy lifestyle, can be avoided by addressing the broader determinants of health [19], and by using a combination of "tailored" interventions, rather than a single mainstream approach. Ethically, moral suasion should be used in a non-judgmental way, however, online HIV / AIDS support group discussions have shown that they can use very harsh terms. A study of pages downloaded from 16 different HIV / AIDS support groups, for example, identified a discussion "thread" in which judgmental, moral group pressure was used to persuade participants to not disclose sero-positivity to their partners [20].

\section{Conclusions}

Over time, in health promotion practice, there has been a shift in professional thinking away from using pre-packaged educational approaches that focus on individual behaviour change and towards collective action. Theories on collective action and organizational change, inter-sectoral action, and the development of healthy public policy now provide opportunities for community empowerment and addressing health inequalities. The lessons learnt have raised our professional awareness for a more balanced approach that increases the effectiveness and sustainability of health promotion programs. What is clear is that this can be best achieved by using a combination of "tailored" interventions rather than using a single mainstream approach alone [21]. The versatility of the moral suasion approach, because it can be readily used in many settings and, in particular, the cost-effectiveness of using "pledges", means that this can be an important intervention alongside other educational and motivational techniques. It is hoped that this paper will help practitioners to better understand how moral suasion and "pledges" can be used to help to change social norms and risky health behaviours, at the individual and collective levels.

Funding: This research received no external funding.

Conflicts of Interest: The author declares no conflict of interest.

\section{References}

1. Seiter, R.H.; Gass, J.S. Persuasion, Social Influence, and Compliance Gaining, 4th ed.; Allyn \& Bacon: Boston, MA, USA, 2010.

2. Gallarotti, G. Soft power: What is it, why is it important and the conditions for its effective use. J. Polit. Power 2011, 4, 25-47. [CrossRef] 
3. Laverack, G. Public Health: Power, Empowerment \& Professional Practice, 3rd ed.; Palgrave Macmillan: London, UK, 2016.

4. Berridge, V. Public health activism. Br. Med. J. 2007, 335, 1310-1312. [CrossRef] [PubMed]

5. Mackie, G. Ending Foot-binding and Infibulation: A Convention Account. Am. Sociol. Rev. 1996, 61, 999-1017. [CrossRef]

6. HESTA Helps Lead Global Push to End Tobacco Financing. 2018. Available online: https://www. hesta.com.au/content/dam/hesta/Documents/media/2018-Tobacco-Free-finance-pledge.pdf (accessed on 15 October 2018).

7. Johansen, E.; Diop, N.; Laverack, G.; Leye, E. What works and what does not: A discussion of popular approaches for the abandonment of Female Genital Mutilation. Obstet. Gynaecol. Int. 2013, 2013, 348248. [CrossRef] [PubMed]

8. Gillespie, D.; Melching, M. The transformative power of democracy and human rights in non-formal education: The case of Tostan. Adult Educ. Q. 2010, 60, 5477-5498. [CrossRef]

9. Huffman, M. Advancing the practice of health coaching. Workplace Health Saf. 2016, 64, 9400-9403. [CrossRef] [PubMed]

10. Wolever, R.; Dreusicke, M.; Fikkan, J.; Hawkins, T.; Yeung, S.; Wakefield, J.; Duda, L.; Flowers, P.; Cook, C.; Skinner, E. Integrative health coaching for patients with type 2 diabetes: A randomized clinical trial. Diabetes Educ. 2010, 36, 4629-4639. [CrossRef] [PubMed]

11. Vale, M. Coaching patients on achieving cardiovascular health (COACH): A multi-center randomized trial in patients with coronary heart disease. Arch. Intern. Med. 2003, 163, 2775-2783. [CrossRef] [PubMed]

12. Seaverson, T.; Staufacker, E.; Tanaka, A. The effectiveness of a telephone-based tobacco cessation program offered as part of a worksite health promotion program. Popul. Health Manag. 2011, 14, 3117-3125.

13. Healthtrainers Healthtrainers: Inspiring You to Live a Healthier Lifestyle. 2018. Available online: http: / / nhs-health-trainers.co.uk/ (accessed on 2 July 2018).

14. Thomas, S.; Olds, T.; Pettigrew, S.; Yeatman, H.; Hyde, J.; Dragovic, C. Parent and child reactions with two contrasting anti-obesity advertising campaigns: A qualitative analysis. BMC Public Health 2014, 14, 1-11. [CrossRef] [PubMed]

15. Lennon, R.; Rentfro, R.; O'Leary, B. Social marketing and distraction during behaviors among young adults: The effectiveness of fear-based campaigns. Acad. Mark. Stud. J. 2010, 14, 95-113.

16. Ritter, A.; Cameron, J. A review of the efficacy and effectiveness of harm reduction strategies for alcohol, tobacco and illicit drugs. Drug Alcohol Rev. 2006, 25, 611-624. [CrossRef] [PubMed]

17. Marlatt, G.A.; Witkiewitz, K. Update on Harm-Reduction Policy and Intervention Research. Annu. Rev. Clin. Psychol. 2010, 6, 591-606. [CrossRef] [PubMed]

18. Fleming, A. Alcohol-Free Months Are All the Rage-But Will a Sober October Lead to Long-Term Health Benefits? The Guardian. Available online: https://www.theguardian.com/lifeandstyle/2018/sep/17/ alcohol-free-months-are-all-the-rage-but-will-a-sober-october-lead-to-long-term-health-benefits (accessed on 18 September 2018).

19. Wilkinson, R.G. (Ed.) Social Determinants of Health: The Solid Facts, 2nd ed.; WHO Regional Office for Europe: Copenhagen, Denmark, 2003.

20. Rier, D. The impact of moral suasion on Internet HIV/AIDS support groups: Evidence from a discussion of seropositivity disclosure ethics. Health Sociol. Rev. 2007, 16, 237-247. [CrossRef]

21. Laverack, G. 'Leaving no one behind': The challenge of reaching migrant populations. Challenges 2018, 9, 37. [CrossRef]

(C) 2018 by the author. Licensee MDPI, Basel, Switzerland. This article is an open access article distributed under the terms and conditions of the Creative Commons Attribution (CC BY) license (http:/ / creativecommons.org/licenses/by/4.0/). 